\title{
Public Health and Patient Care Aspects in Indian Pharmacy Curricula: A Comparison with USA, Finland and Denmark
}

\author{
Siva Prasada Reddy Maddirala Venkata ${ }^{1 *}$, Peter Kielgast ${ }^{2}$, Ubaidulla Udhumansha ${ }^{3}$ and Marja \\ Airaksinen $^{4}$
}

\author{
${ }^{1}$ Clinical Pharmacy Group, Division of Pharmacology and Pharmacotherapy University of Helsinki, Viikinkaari 5 E, Biocenter 200014 \\ Helsinki Finland, Taastrup Hovedgade 60, Taastrup, DK-2630, Denmark. \\ 2Proprietor Pharmacist, Taastrup Pharmacy, Taastrup Hovedgade 60, Taastrup, DK-2630-Denmark. \\ ${ }^{3}$ Department of Pharmaceutics, C. L. Baid Metha College of Phrmacy Jyothi Nagar, Rajiv Gandhi SalaiThorapakkam, Chennai- 600 \\ 097, India. \\ ${ }^{4}$ Professor of Social Pharmacy, Clinical Pharmacy Group, Division of Pharmacology and Pharmacotherapy University of Helsinki \\ Viikinkaari 5 E, Biocenter -200014 Helsinki Finland.
}

\begin{abstract}
$\operatorname{Aim}(\mathbf{s})$ : This study was designed to compare Indian pharmacy curricula with Pharmacy curriculum of USA, Finland and Denmark to assess differences with a focus on pharmaceutical policies and public health, patient care and pharmacy practice aspects in the programs. Study Design: This is a programmatic research conducted between March 2013 and August 2014. Methods: Curricula of pharmacy programs leading to registered pharmacist in India, USA, Finland and Denmark were selected. By using conversion references, all curricula were converted into number of hours-format to make them comparable. The curriculum contents were divided into four core areas and number of hours were collated and analyzed. Results: The proportions of 4 core areas remarkably vary between the curricula assessed. Diploma in Pharmacy (D Pharm) and Bachelor of Pharmacy (B Pharm) programs in India are allocating about $60 \%$ of total time to pharmaceutical sciences against National Association of Boards of Pharmacies's (NABP) Pharmacy Curriculum Outcomes Assessment (PCOA) recommended 30\%. D Pharm curriculum is covering $12 \%$ (175 hours), B Pharm and Doctor of Pharmacy (Pharm D) cover $8 \%$ (315 hours and 462 hours, respectively) against PCOA recommended $22 \%$ of social/behavioral/administrative sciences. Indian D Pharm covers $8 \%$ (125 hours) and BPharm 2\% (90 hours) of clinical sciences, while Indian Pharm D covers $36 \%$ which is in par with PCOA recommendation (32\%). Finnish and Danish curricula have more electives when compared to Indian curricula. Pharmaceutical policy and public health topics are least allocated in all the programs studied. Conclusion: Indian and US Pharm D programs contain most and Indian D Pharm and B Pharm least public health and patient care aspects. Consequently, India has high number of trained pharmacists, but curriculum is industry focused, although they work in community pharmacies. It is important that the workforce and competency needs of pharmaceutical industry are met. It would be useful to have an alternative curriculum line focusing on patient care and pharmacy practice aspects in Indian D Pharm and B Pharm programs. Further research is needed to assess how well current D Pharm, B Pharm and Pharm D curricula prepare graduating pharmacists to contribute to public health and patient care. This study is first of its kinds, it will be helpful to statutory authorities and curriculum reform committees in India and other countries where pharmacists' role is continuing to evolve towards inclusion of public health and patient care.
\end{abstract}

Key words: Curriculum Comparison, Pharmacy Education, Pharmacy Curriculum, Patient Care, Public Health, India.

\section{INTRODUCTION}

Pharmacists represent the third largest after nurses and doctors/physicians. ${ }^{1}$ Public health care professional group in the world health deals with improving health or pre-
Submission Date : 28-06-2015 Revision Date : :01-09-2015 Accepted Date : :24-08-2015

DOI: 10.5530/ijper.50.1.1 Correspondence Address Mr. Siva Prasada Reddy Maddirala Venkata

Clinical Pharmacy Group, Division of Pharmacology and Pharmacotherapy, University of Helsinki Viikinkaari5E, Biocenter 200014 Helsinki

Finland. Taastrup Pharmacy, Taastrup Hovedgade 60 Taastrup, DK-2630, Denmark.

Email:prassu117@yahoo. com

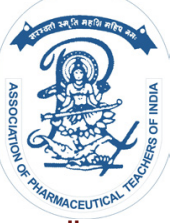

www.ijper.org 
venting illness in a population, and public health programs are usually coordinated by the government or a group/body accountable to a community. ${ }^{2}$ Improving public health in any country requires intersectoral action and combined efforts of people from various professions and disciplinary backgrounds. ${ }^{3}$ Public health systems in many countries have shortage of medical and paramedical personnel. Government of India estimates, based on vacancies in sanctioned posts, that $18 \%$ of primary health centers are without a doctor, about $38 \%$ are without a laboratory technician, and $16 \%$ are without a pharmacist. ${ }^{4-5}$ There are over one million registered pharmacists in India working in various facets of pharmacy. ${ }^{6-7}$

In 1994, World Health Organization's (WHO) resolution from World Health Assembly, WHA 47.12 recognized the key role of pharmacists in public health, particularly in the field of medicines, ${ }^{8}$ which should reflect to curriculum content. The Resolution emphasized pharmacists' responsibility to provide advice on medicines and their use, to promote the concept of pharmaceutical care, and to actively participate in illness prevention and health promotion. In contrast to that, the national health and pharmaceutical policies of India have not recognized and charted pharmacists' role. This huge workforce is not officially a part of health care team. If this workforce is motivated and properly trained, they can become tremendous potential for improving public health.

In global pharmacy and pharmaceutical education initiatives, the call for circular reform has been raised by International Pharmaceutical Federation (FIP). ${ }^{9}$ In developed countries, patient-centered curricula and public health pharmacy are focused on tackling everchanging health environments. ${ }^{10}$ If the full potential of pharmacists is to realize in India, their expertise in medicine management should be utilized to make them part of national health and pharmaceutical policies, the curriculum of different Indian pharmacy education programs needs to ensure that pharmacists are able to take their role in patient-centered activities and national public health programs. For this purpose, it is important to assess curriculum for public health and patient care aspects and compare with other countries where there is more emphasis and exposure on these aspects.

\section{AIM OF THE STUDY}

The aim of this study was to compare Indian pharmacy curriculum of Diploma in Pharmacy (D Pharm), Bachelor of Pharmacy (B Pharm) and Doctor of Pharmacy (Pharm D) with Pharmacy curriculum of USA, Finland and Denmark to see overall differences with a focus on the amount of time devoted in the programs for pharmaceutical policies and public health, patient care and pharmacy practice aspects.

\section{METHODS}

To achieve the objective of the study, this programmatic research was designed to compare curriculum of Indian pharmacy education programs (D Pharm, B Pharm and Pharm D) with the pharmacy curriculum of Denmark, Finland and USA, where pharmacy is being practiced with patient care in focus. The study was conducted between March 2013 and August 2014.

\section{Selection of countries}

WHO Member States are grouped into 6 WHO regions: African Region, Region of the Americas, Eastern Mediterranean Region, European Region, South East Asia Region (SEAR) and Western Pacific Region (WPR). ${ }^{11}$ India covers the largest part in SEAR, USA is an important member of Region of America, and Finland and Denmark are from Europe Region. Though countries like Australia from WPR and UK in European Region demonstrate patient focused pharmacy practice, the comparison was limited to USA, Denmark and Finland. This is because the most remarkable professional philosophies guiding globally recent patient focused and clinical based pharmacy practice development originate from the USA. ${ }^{12}$ Pharmacists in Northern Europe seem to be best positioned in health care chain to detect, prevent, and correct drug-related problems. ${ }^{13}$

\section{Selection of curricula}

Syllabus of Indian Pharmacy courses leading to registered pharmacist title, D Pharm, B Pharm and Pharm D were collected. The syllabus for D Pharm ${ }^{14}$ and Pharm $\mathrm{D}$ programs are uniform throughout the nation with the same subjects, chapters and number of teaching hours per year as prescribed under the Pharmacy Council of India (PCI) Education Regulations 1991 and Pharm D Regulations $2008,{ }^{15}$ respectively, which were used for the comparison. It is mandatory for all the colleges conducting D Pharm and Pharm D programs to follow the syllabus prescribed by PCI under the relevant Acts. As per the Clause 10(i) of the All India Council for Technical Education (AICTE) Act 1987, ${ }^{16}$ it is mandatory for all the AICTE approved B Pharm programs to maintain the uniformity in accordance with the Model Curriculum. In fulfillment of this Clause, a Model Curriculum for B Pharm is prescribed by AICTE in $2011^{16}$ which was used for comparison in this study. This curriculum is a guideline for the universities, and hence, $\mathrm{B}$ 
Pharm curriculum from randomly selected two different universities is tested to see if they are in-line with the Model Curriculum of AICTE. Both these universities have approximately the same amounts of core subject areas (2-5 percent variation). ${ }^{17}$

USA Pharm D curriculum was randomly selected from the University of Florida. Master of Science in Pharmacy programs from the University of Helsinki, Finland, and the University of Copenhagen, Denmark were used for comparison.

\section{Conversion of credits into hours}

Selected Indian curricula were available in number of hours. However, other selected curriculums were available in number of credits. The University of Florida curriculum is defined in credits, where each credit is equivalent to 17 hours. ${ }^{18}$ One ECTS credit (European Credit Transfer and Accumulation System) of Finnish and Danish curriculum is equivalent to 27 hours of student work. ${ }^{19-20}$ Using these conversion references, all curriculums included in this study were converted into number of hours-format to make them comparable.

\section{Division of core curriculum content and comparison}

This study applied the same method as was used in a previous study which defined the curriculum content and compared existing pharmacy curricula in India in terms of public health and patient care aspects. ${ }^{17}$

The curriculum content from each study curriculum was divided into the following four core areas: Area 1: Basic Biomedical Sciences, Area 2: Pharmaceutical Sciences, Area 3: Social/Behavioral/Administrative Sciences, and Area 4: Clinical Sciences; as outlined in Appendix$B$ of Accreditation Council for Pharmacy Education's (ACPE) "Accreditation standards and guidelines for the professional program in pharmacy leading to the doctor of pharmacy degree, 2011 version". ${ }^{21}$ The core curriculum areas from each program were tabulated and the results were analyzed and compared with a focus on Social/Behavioral/Administrative Sciences and Clinical Sciences areas. In Core area 3: health and pharmaceutical policies, practice management, pharmaco economics, pharmaco epidemiology, pharmacy law, regulatory affairs, ethics, professional communication, social and behavioral aspects of practice both community and hospital pharmacy practice were collated. In Core area 4: pharmacotherapy, drug information, medication safety and literature evaluation and research design aspects were collated. Special focus was made to see if there is emphasis on patient care (for example efforts to improve therapeutic outcomes by counseling, disease and medicine management, maintaining patient profiles), health and pharmaceutical policies and public health programs (for example knowledge and preparation to take part in national health programs, such as HIV/AIDS control, Tuberculosis control, Vector Borne disease control, Leprosy eradication, Pulse polio, Universal vaccination and Tobacco eradication programs) in the curriculum.

From each curriculum collated number of hours from each core area was separated as described in ACPE's accreditation standards and guidelines and the National Association of Boards of Pharmacies's (NABP) Pharmacy Curriculum Outcomes Assessment (PCOA) guidelines. ${ }^{22}$ Subjects from each program were divided into theory lectures and practical hours in the laboratory. Theory hours are defined as the class-room teaching on chapters from curriculum by the lecturers/professors. The practical hours are defined as hours spent in laboratory or in a practical setting.

\section{RESULTS}

Table 1 shows an overview of pharmacy programs available in four selected countries, length of each pharmacy program, regulatory body responsible for pharmacist registration and additional assessment examinations required to pass to obtain pharmacist registration.

\section{Pharmacy education in India}

Minimum qualification for registration and practice of pharmacy in India is a pass in either of D Pharm or B Pharm or Pharm D programs from PCI approved institution with 3 months internship for D Pharm and B Pharm and 12 months internship for Pharm D (Table 1). Pharmacy education in India is regulated by 2 statutory bodies: Pharmacy Council of India and All India Council for Technical Education. Indian pharmacy graduate does not need to take any additional assessment examinations to practice pharmacy.

\section{Pharmacy education in USA}

USA has Pharm D as the only program to practice the pharmacy in the country as a pharmacist (Table 1). Pharm D programs at all US universities must be accredited by the Accreditation Council for Pharmacy Education (ACPE), the national agency for accreditation of professional degree programs in pharmacy and providers of continuing pharmacy education. ${ }^{23}$ Schools of Pharmacy offering the traditional Master of Science in Pharmacy (MSc Pharm) and $\mathrm{PhD}$ programs prepare students for teaching and research careers. In USA, after successful completion of Pharm D, one cannot directly register as pharmacist and start practicing pharmacy. The graduates with PharmD, willing to practice phar- 


Tablet 1: An overview of pharmacy programs leading to registered pharmacist in India, USA,
Denmark and Finland

*Internship program = practical training in hospitals/dispensaries and/or in a community pharmacy and/or drugs manufacturing unit. ${ }^{1}$ According to European Union regulations, minimum 3 months of the 6-months internship must be done in a community pharmacy. The remaining 3 months can be done in a hospital or community pharmacy ${ }^{20}$

macy must also: i) complete internship, whose length vary for each state, ii) pass North American Pharmacist Licensure Examination (NAPLEX), and iii) Multistate Pharmacy Jurisprudence Examination (MPJE) state law examination which is conducted by State Pharmacy Boards. Moreover, proof of completing continuing education in programs approved by the Accreditation Council for Pharmacy Education (ACPE) is required for renewal of pharmacist license.

\section{Pharmacy education in Denmark}

To become registered pharmacist and/or to own a pharmacy in Denmark, minimum qualification required is MSc degree in pharmacy ${ }^{24}$ (Table 1). MSc degree from Danish University of Pharmaceutical Sciences is the oldest program in Denmark. University of Southern Denmark is also offering both BSc and MSc in pharmacy programs duly recognized to register as a pharmacist which is accredited by the Danish Accreditation Institute (ACE Denmark). ${ }^{25}$ In Denmark, upon successful completions of MSc (Pharm) degree with 6 months internship (altogether 5 years), there are no additional exams required to be completed for becoming registered pharmacist and to practice pharmacy.

\section{Pharmacy education in Finland}

Finland has adopted a 2-tier university training program for pharmacists consisting of BSc and MSc degrees, which is in line with the Bologna Declaration harmo- nizing structures of the European university degrees ${ }^{12,16}$ (Table 1).The BSc degree consists of 180 ECTS credits and it takes 3 years to complete. The MSc degree takes an additional 2 years to complete (total 300 ECTS credits). ${ }^{14}$ MSc level pharmacists mostly work in managerial and leadership positions and in positions requiring advanced pharmaceutical expertise. A majority of BSc pharmacists work in community pharmacies being responsible for dispensing, patient counseling and customer service. Only MSc pharmacists can own a pharmacy. ${ }^{20}$

In addition to the minimum requirements specified in Directive 2005/36/EC of the European Union and of the Council for Pharmaceutical Education, students pursuing the BSc (Pharm) and MSc (Pharm) degree must obtain professional and practical competencies in areas determined nationally important for pharmacists to acquire during their basic education. An essential part of BSc (Pharm) curriculum in Finland is an obligatory internship of 6 months (30 ECTS credits), which is integrated with professional study at the university. ${ }^{20}$ The internship can be taken in a community pharmacy which is open to the public (minimum 3 months/15 ECTS credits), or in a hospital under supervision of that hospital's pharmaceutical department (maximum 3 months/15 credits). 2,16,20

Finnish BSc and MSc degrees are designed to prepare students for professional practice. The curriculum has elective courses both in the bachelor's and master's degree. The master's degree aims at developing further the students' scientific skills and includes an obligatory6month research project (Master's thesis, 40 ECTS cred- 


\begin{tabular}{|c|c|c|c|c|c|c|c|c|c|c|c|c|c|}
\hline \multirow[t]{2}{*}{ Core Area } & \multicolumn{2}{|c|}{$\begin{array}{l}\text { DPharm } \\
\text { India: }\end{array}$} & \multicolumn{2}{|c|}{$\begin{array}{c}\text { BPharm India: } \\
\text { Total hours } \\
3750\end{array}$} & \multicolumn{2}{|c|}{$\begin{array}{c}\text { PharmD } \\
\text { India: } \\
\text { Total hours } \\
5709\end{array}$} & \multicolumn{2}{|c|}{$\begin{array}{l}\text { MSc Pharm } \\
\text { Finland: } \\
\text { Total hours } \\
8100^{*}\end{array}$} & \multicolumn{2}{|c|}{$\begin{array}{l}\text { MSc Pharm } \\
\text { Denmark: } \\
\text { Total hours } \\
8400^{* *}\end{array}$} & \multicolumn{2}{|c|}{$\begin{array}{c}\text { PharmD USA: } \\
\text { Total hours } \\
2482\end{array}$} & \multirow{2}{*}{$\begin{array}{c}\mathrm{PCOA}^{* * *} \\
\\
\%\end{array}$} \\
\hline & $\%$ & Hours & $\%$ & Hours & $\%$ & Hours & $\%$ & Hours & $\%$ & Hours & $\%$ & Hours & \\
\hline $\begin{array}{l}\text { Basic and Biomedical } \\
\text { sciences }\end{array}$ & 17 & 250 & 31 & 1155 & 18 & 1056 & 10 & 783 & 12 & 980 & 12 & 306 & 16 \\
\hline $\begin{array}{l}\text { Pharmaceutical } \\
\text { Sciences }\end{array}$ & 63 & 950 & 58 & 2190 & 37 & 2112 & 28 & 2241 & 40 & 3374 & 13 & 323 & 30 \\
\hline $\begin{array}{c}\text { Social/behavioral/ } \\
\text { administrative Sciences }\end{array}$ & 12 & 175 & 8 & 315 & 8 & 462 & 15 & 1188 & 7 & 560 & 8 & 204 & 22 \\
\hline Clinical Sciences & 8 & 125 & 2 & 90 & 36 & 2079 & 14 & 1107 & 16 & 1386 & 66 & 1649 & 32 \\
\hline
\end{tabular}

* Finnish MSc (Pharm) curriculum has electives 2781 hours (34\%) of the curriculum

** Danish MSc (Pharm) curriculum has electives 2100 hours $(25 \%)$ of the curriculum

*** Pharmacy Curriculum Outcomes Assessment Guidelines of National Association of Boards of Pharmacy, USA

its). ${ }^{26}$ In Finland, both BSc (3 years) and MSc (5 years) of pharmacy can register and practice as pharmacist, however, only pharmacists with a MSc degree may own a community pharmacy. ${ }^{27}$ Both the bachelors and masters programs have personal study plan which is approved by the professor or other nominated senior instructor. The personal study plan gives flexibility to the students to choose their area of interest. Students interested in community pharmacy practice, and social and clinical pharmacy can plan their studies and become experts. In Finland, graduates with bachelor's (BSc) and master's (MSc) degree in pharmacy do not need additional exams to become registered pharmacist and practice pharmacy.

\section{Core area 1: basic and biomedical sciences}

Indian pharmacy programs are covering more basic and biomedical sciences compared to Denmark, Finland and USA (Table 2). This applies particularly to Indian B Pharm program, of which $31 \%$ of the total hours are related to basic and biomedical sciences. The corresponding proportions in Indian D Pharm and Pharm D programs are $17 \%$ and $18 \%$, respectively. In other study countries the proportion is $10-12 \%$.

\section{Core Area 2: pharmaceutical sciences}

The proportion of pharmaceutical sciences in pharmacy programs varies a lot between countries and degrees (Table 2). Both D Pharm and B Pharm programs in India are allocating about $60 \%$ of total time to pharmaceutical sciences. Indian Pharm D curriculum is covering 2112 hours of pharmaceutical sciences, which is higher than suggested PCOA percent (37\% vs. $30 \%$, respectively).

\section{Core Area 3: Social/behavioral/administrative sciences}

Social/behavioral/administrative sciences can be considered as the backbone subjects to public health oriented pharmacy practice. PCOA is recommending $22 \%$ of the curriculum to be devoted to social/behavioral/ administrative sciences, but none of the test programs are covering recommended amount of time. D Pharm curriculum in India is covering 12\% (175 hours), B Pharm and Pharm D are covering 8\% (315 hours and 462 hours, respectively). Finnish MSc (Pharm) has 15\% (1188 hours) which is highest among all. Indian programs are lacking course work in behavioral and social sciences, health care policy, patient counseling and communication aspects. ${ }^{28}$

\section{Core Area 4: clinical sciences}

This core area gives proper knowledge to practicing pharmacists to provide patient care that optimizes the use of medication and promotes health, wellness, and disease prevention. ${ }^{29}$ By spending more number of hours in clinical sciences, pharmacists can acquire knowledge to offer better patient care to enhance therapeutic outcomes. PCOA recommends devoting $32 \%$ of the time for clinical sciences. However, Indian D Pharm and B Pharm are covering $8 \%$ (125 hours) and 2\% (90 hours) of clinical sciences, respectively. Pharm D curriculum is covering $36 \%$ of clinical sciences which is in par with the PCOA recommendation (32\%).The US-Pharm D program has $66 \%$ (1649 hours) of clinical sciences which is more than 2 -fold compared to the PCOA recommendation.

\section{DISCUSSION}

There are about 717 colleges conducting D Pharm, 968 colleges conducting B Pharm and 160 colleges conducting 
Pharm D and Pharm D degree (Post Baccalaureate) programs in India. ${ }^{17,} 30$ India has provision for over 100,000 pharmacy student admissions each year, which includes D Pharm, B Pharm and Pharm D degrees. ${ }^{16}$ Core areas supporting public health and patient care aspects, i.e., clinical sciences and social/behavioral and administrative sciences cover remarkably smaller proportion of Indian D Pharm and B Pharm programs than recommended by PCOA. The same applies to pharmacy programs in Denmark and Finland, whereas the proportion in the Indian Pharm $\mathrm{D}$ program is closest to the recommended proportion ( $44 \%$ vs. $54 \%$ recommended). The US Pharm D program exceeds the recommendation in clinical sciences, but is low in contents related to social, behavioral and administrative sciences ( $8 \%$ vs. $22 \%$ recommended).

Of the pharmacy programs evaluated, Indian D Pharm curriculum is the shortest one leading to pharmacist degree. D Pharm holders with a 2-year training are mainstays of community pharmacy practice, but diploma curriculum least contains public health and patient care aspects. About $60 \%$ of time being spent in pharmaceutical sciences in Indian D Pharm and B Pharm programs, it is evident that these programs are science and industry oriented programs, but not patient care and practice oriented. As a consequence, India has a high number of trained pharmacists, but their training is focused more towards the industrial sector although they work in community pharmacies. It is important that the workforce and competence needs of the pharmaceutical industry are met. At the same time, it would be useful to have an alternative curriculum line focusing on patient care and pharmacy practice aspects in D Pharm and B Pharm programs. If the profession has to have skilled workforce both in industry and practice areas, it needs constant curriculum evaluation and reform process, like in Finland and USA. ${ }^{17}$ Curriculum evaluation and reforms were least prioritized for both D Pharm and B Pharm programs, ${ }^{17}$ which may be one of the several reasons for not developing the curriculums to support patient care oriented pharmacy practice in India.

The option for community pharmacy and health care orientation in addition to current industry orientation in Indian pharmacy curricula is supported by the existing deployment needs. The pharmacists' deployment chart presented at the International Conference on Improving Use of Medicines (2004) showed that, of all categories of pharmacists in India, 51\% worked in retail pharmacy, $26 \%$ in hospital pharmacy, $8 \%$ of each in industry and higher studies, $5 \%$ in marketing, and the rest in teaching, drug regulatory authorities, and analytical chemists. ${ }^{31-32}$ At that time, the statistics concerned pharmacists with
D Pharm and B Pharm degree as the Pharm D training was started in 2008 in India. ${ }^{32}$

Findings from this comparison indicate that India has come to a situation of having different types of pharmacy programs with a wide variation in length and content. This will create huge knowledge and competence gaps within the profession with the same professional titles, which will give chance for inter-professional disputes. The question that rises is whether $\mathrm{D}$ Pharm with a 2-year training can continue to be as the minimum qualification to practice pharmacy. With nearly $50 \%$ less in terms of total number of hours, Indian D Pharm curriculum is very short and is not comparable to such pharmacy programs as Pharm D in India and USA, and MSc in Finland and Denmark.

Indian D Pharm program could be converted similar to Finnish 3-year BSc program which is practice-oriented university degree with quite a good proportion of social, behavioral and administrative sciences, and electives..$^{27}$ Also the obligatory 6 -months internship is designed to support development of pharmacy practice competences, particularly, patient counseling and medication management skills. ${ }^{20,27}$ Another option could be to restructure D Pharm program similar to Danish pharmaconomist (pharmacy assistant) program. ${ }^{17}$ It is a 3-year vocational program mostly based on workplace training coordinated by a training center (Pharmak on) run by the Danish pharmacy owners association. Danish pharmacies provide cognitive services guided by a protocol for their delivery. The services can be provided by pharmacists and pharmaconomists. ${ }^{25}$ The pharmaconomist cannot own or run a pharmacy, but can perform most of the pharmacist's duties with some limitations, such as medication reviews, dosage corrections and interventions in the prescriptions, which should be done in cooperation with the registered pharmacist. Pharmaconomists can operate pharmacy outlets or medicine delivery facilities ${ }^{25}$ as can also Finnish BSc pharmacists.

Our results confirm that the Indian Pharm D program is directed at clinically oriented pharmacy practice with a recommended proportion of training hours in clinical sciences. ${ }^{30}$ The curriculum has less than recommended course work in behavioral and social sciences, health care policy, patient counseling and communication aspects. ${ }^{29}$ Pharmacists' knowledge in medicines and clinical therapeutics make them suitable to place in task shifting in health care. As Pharm D is newly introduced program in India, it is important to evaluate the results of the program and make necessary reforms frequently. The regular evaluation has been done for example in the University of Helsinki. ${ }^{33}$ These assessment procedures 
are an integral part of the faculty's quality assurance program. The evaluation can involve faculty members, students, practitioners and a wide range of stakeholders with working life experience from different sectors. ${ }^{27}$

The current ACPE standards allow colleges and schools to pursue the development of student experiences that will utilize best practices in service learning, plus fulfill the need of introductory practice experiences. ${ }^{34}$ To gear up the future pharmacists for new roles, introduction of community service in the pharmacy curriculum for D Pharm and B Pharm courses is suggested. This can be achieved through advanced pharmacy practice experiences (APPEs) as being practiced in USA, where students can be inspired, empowered, and take notice of what is lacking in the scope of practice of a pharmacist, in hopes that they will one day be driven to seek ways to enact changes within the profession. The first step in discovering how public health and pharmacy merge on a macrocosmic level is by raising student awareness.

This is the first published comparison of Indian pharmacy curriculum with some other countries having more emphasis on public health and patient care aspects in their pharmacy curriculum. Number of Indian pharmacists and pharmacy colleges could be counted as great human resources for health in India. If proper planning is made by the profession and policy makers, pharmacists can play an important role in public health and patient care.

\section{STUDY LIMITATIONS}

The strength of this study was use of national curricula for D Pharm and Pharm D from PCI, and for B Pharm program the model curriculum suggested by AICTE. Selection of University of Florida curriculum to represent entire USA is a limitation, as all the US universities follow the ACPE guidelines, but they can modify the curriculum as per their needs.

Selection was limited to four countries form three WHO regions. A wider range of selection from Western Pacific, Eastern Mediterranean Regions and African Regions would have given more insights. Particularly, inclusion of UK and Australian curricula could have provided more insights in public health and patient care orientation in pharmacy curricula, and thus, enriched our analysis. However, the comparison was limited to India, USA, Finland and Denmark on the basis of the reasons given in the Methods Section.

\section{CONCLUSION}

The US and Indian Pharm D programs contain most and the Indian D Pharm and B Pharm least public health and patient care aspects of all the six pharmacy programs were assessed. As a consequence, India has a high number of trained pharmacists, but their training is focused more towards the industrial sector although they work in community pharmacies. It is important that the workforce and competence needs of the pharmaceutical industry are met. At the same time, it would be useful to have an alternative curriculum line focusing on patient care and pharmacy practice aspects in Indian D Pharm and B Pharm programs. Further research is needed to assess how well current D Pharm, B Pharm and Pharm D curricula prepare graduating pharmacists to contribute to public health and patient care services in India. As this study is the first of its kind, it will be helpful to the statutory bodies and curriculum reform committees in India and other countries where pharmacists' role is continuing to evolve towards inclusion of direct public health and patient care.

\section{ACKNOWLEDGEMENTS}

We wish to thank Mr. Prafull D. Sheth, former Vice President, FIP; Professor B. Suresh, President, Pharmacy Council of India and Vice Chancellor, JSS University, Mysore, India; Professor Roop K. Khar, Principal, B. S. Anangpuria Institute of Pharmacy, Faridabad, India; Dr. LoganathanVeerappan, Taylor's University, Malaysia; MikeRouse, Director, International Services, Accreditation Council for Pharmacy Education (ACPE), USA; Professor Sven A. Normann, University of Florida, USA; RiittaKoistinen, University of Eastern Finland, Finland; Helena Huhtala, University of Helsinki, Finland; and Associate Professor BenteSteffansen, University of Copenhagen, Denmark for their assistance during the preparation of this article.

\section{CONFLICT OF INTEREST}

The authors contributing to this study and manuscript have no conflict of interests.

\section{ABBREVIATION}

$\begin{array}{ll}\text { PCI } & : \text { Pharmacy Council of India } \\ \text { AICTE } & : \text { All India Council for Technical } \\ & \text { Education } \\ \text { NAPLEX } & : \text { North American Pharmacist Licen } \\ & \text { sure Examination }\end{array}$


MPJE

\author{
: Multistate Pharmacy Jurisprudence \\ Examination
}

\section{REFERENCES}

1. Sachan A, Sachan A K, Gangwar S S. Pharmacy education in India and its neighbouring countries. IntCurr. Pharm. J. 2012; 1(9): 294-301.

2. Hine D. Public Health at the Crossroads: Achievements and Prospects. J R Soc Med. 2004; 97(9): 450-1.

3. F Sim, K Lock, M McKee. Maximizing the contribution of the public health workforce: the English experience. Bull World Health Organ. 2007; 85(12): 901-80.

4. Government of India. Bulletin on rural health statistics 2008 (2009). http:// www.pbnrhm.org/docs/bulletin_rural_health_statistics.pdf. Accessed October 18, 2014.

5. Rao M, Rao K D, Shiva Kumar A K, Chatterjee M, Sundararaman T. Human resources for health in India. The Lancet 2011; 377(9765): 587-98.

6. Pharmacy Council of India. Circular on Declaration of Pharmacists Day. Ref. No. 10-1/2007-PCl (A)/21853-23908. http://www.pci.nic.in/Circulars/ Pharmacist\%20Day.pdf. Accessed February 28, 2014.

7. Praneta D., An overview about pharmacy education in India. Ind. J. Res. Pharm. Biotech. 2013; 1(3): 329-32.

8. Forty-Seventh World Health Assembly. Resolution WHA 47.12, Role of the pharmacist in support of the WHO revised drug strategy. http://www. europharmforum.org/file/7412. Accessed October 18, 2014.

9. International Pharmaceutical Federation. FIP Ed Global education report 2013 https://fip.org/static/fipeducation/2013/2013-FIPEd-GlobalEducationReport/ index.html\#/36. Accessed October 18, 2014

10. Anderson C, Bates I, Brock T, Brown A N, Bruno A, Rennie B F T, and Rouse MJ. Needs-based education in the context of globalization. Am J Pharm Educ. 2012; 76(4): 56.

11. World Health Organization, About WHO and regional offices. http://www.who. int/about/regions/en/. Accessed October 18, 2013.

12. Hepler C D, Strand L M. Opportunities and responsibilities in pharmaceutical care. Am J Hosp Pharm. 1990; 47(3): 533-43.

13. van Mil J W Foppe and Schulz M. A Review of Pharmaceutical Care in Community Pharmacy in Europe. Health Highlights. 2006; 7(1):155-68.

14. Pharmacy Council of India Education Regulations, 1991 for the diploma in pharmacy, Chapter 2. http://pci.nic.in/RulesRegulations/ EducationRegulations1991/Chapter2.aspx. Accessed October 18, 2014.

15. The Gazette of India, no.19, Part III, Section 4, PharmD Regulations 2008. http://pci.nic.in/PDF-Files/PharmD-Revised-A.pdf. Accessed October 18, 2014.

16. All India Council for Technical Education. Model Curriculum for B Pharmacy 2011. http://www.aicte-india.org/downloads/Model_Curriculum_Degree_ Pharmacy_030912.pdf. Accessed October 18, 2014.

17. MaddiralaVenkata $S P R$, Kielgast $P$, Udhumansha $U$, Airaksinen M. Public Health and Patient Care Aspects in Indian Pharmacy Curriculum: A
Comparison between DPharm, BPharm and PharmD Programs. Curr Pharm Teach Learn. 2015; 7(1): 84-93.

18. University of Florida. Credit Conversion. http://warrington.ufl.edu/ undergraduate/intl/outgoing/exchange/denmark_USD.asp Accessed October 18, 2014

19. ECTS Users' Guide 2009. Overview of national regulations on the number of learning hours per academic year. http://ec.europa.eu/education/tools/docs/ ects-guide_en.pdf. Accessed October 15, 20014

20. Löfhjelm U, Pitkä K, Passi S, Airaksinen M. Integration of internship with professional study in pharmacy education in Finland. Am J Pharm Educ. 2014; 78(9): 2-9.21

21. Accreditation Council of Pharmacy Education's (ACPE). Accreditation standards and guidelines for the professional program in pharmacy leading to the doctor of pharmacy degree, 2011 version, Appendix-B. https://www.acpeaccredit.org/pdf/FinalS2007Guidelines2.0.pdf. Accessed October 18, 2014.

22. National Association of Boards of Pharmacies (NABP). Pharmacy Curriculum Outcomes Assessment (PCOA) guidelines. http://www.nabp.net/programs/ assessment/pcoa. Accessed October 18, 2014.

23. Accreditation Council for Pharmacy Education (ACPE). https://www.acpeaccredit.org/about/default.asp. Accessed October 18, 2014.

24. Herborg H, Westh Sørensen E, Frøkjær B. Pharmaceutical Care in Community Pharmacies: Practice and Research in Denmark. Ann Pharmacother.2007; 41(4): 681-9.

25. University of South Denmark. MSc in Pharmacy program. http://www.sdu.dk/ en/uddannelse/kandidat/farmaceut. Accessed October 18, 2014.

26. Katajavuori N, Hakkarainen K, Kuosa T, Airaksinen M, Hirvonen J, Holm Y. Curriculum reform in Finnish pharmacy education. Am J Pharm Educ. 2009; 73(8): 151

27. Bell J S, Väänänen M, Ovaskainen H, Närhi U, Airaksinen M S. Providing patient care in community pharmacies: practice and research in Finland. Ann Pharmacother. 2007; 41(6): 1039-46.

28. Maddirala Venkata S P R, Airaksinen M, Kielgast P. Indian pharmacy curriculum: a comparison with USA, Finland and Denmark. In: E4 Addressing global complexities through educational innovation. 73rd FIP Congress in Dublin (Ireland) 2013.

29. Clinical Pharmacy Defined. Pharmacotherapy. 2008; 28(6): 816-7.

30. Sheth P. D., Frokaer B. Guiding principles for pharmacists in the fight against HIVIAIDS in India. Presented at Second International Conference on Improving Use of Medicines. Chiang Mai, Thailand; 2004.(http://archives.who. int/icium/icium2004/resources/ppt/HI006.pdf); Accessed June 03, 2015.

31. Revikumar K G, Veena R. Doctor of pharmacy education in India-strengths and weaknesses and opportunities, acritical analytical study based on five years existence in India. J HarmonizedResPharm. 2014; 3(2): 30-47.

32. Saari S, Frimodig M. Leadership and management of education, evaluation of education at University of Helsinki 2007-2008.Administrative publication 58, University of Helsinki, 2009.

33. Bartelme K M, Ticcioni A J, Janke K K. Providing health care service-learning experiences for IPPE credit. Innovations in Pharmacy. 2011; 2(3): 47. 